\title{
Fenos de capim-buffel amonizados com ureia
}

\author{
Buffel grass hays ammoniated with urea
}

\author{
BEZERRA, Higor Fábio Carvalho ${ }^{1 *}$; SANTOS, Edson Mauro ${ }^{1}$; OLIVEIRA, Juliana \\ Silva de ${ }^{1}$; PINHO, Ricardo Martins Araujo ${ }^{1}$; PERAZZO, Alexandre Fernandes ${ }^{2}$; \\ SILVA, Ana Paula Gomes da ${ }^{1}$; RAMOS, João Paulo de Farias ${ }^{1}$; PEREIRA, Gildenia \\ Araújo $^{1}$
}

\author{
${ }^{1}$ Universidade Federal da Paraíba, Centro de Ciências Agrárias, Departamento de Zootecnia, Areia, \\ Paraíba, Brasil. \\ ${ }^{2}$ Universidade Federal da Bahia, Escola de Medicina Veterinária e Zootecnia, Departamento de Medicina \\ Veterinária e Zootecnia, Salvador, Bahia, Brasil. \\ *Endereço para correspondência: higorfabiozoo@hotmail.com
}

\section{RESUMO}

Objetivou-se quantificar a população de mofos e leveduras, avaliar as perdas de matéria seca e a composição bromatológica de fenos de capimbuffel amonizados com ureia. Utilizou-se um delineamento inteiramente casualizado, com cinco tratamentos e cinco repetições. Os tratamentos compreenderam aos níveis de ureia $(0 ; 0,5 ; 1,0$; 2,$0 ; 4,0 \%$ ), que foram adicionados aos fardos de feno com base na matéria seca. A inclusão de $1,0 \%$ de ureia elevou a recuperação de matéria seca $(93,21 \%)$ em relação ao feno não amonizado. Observou-se efeito quadrático para o $\mathrm{pH}$, com o maior valor observado no nível de $0,5 \%$ de ureia $(8,88)$, reduzindo nos demais níveis de ureia. A adição de níveis de ureia foi eficiente em reduzir a população de mofos e leveduras, reduzindo de 6,50 log UFC/g no feno sem tratamento com ureia para 3,65 log UFC/g quando adicionados $4 \%$ de ureia no feno. A adição de ureia proporcionou aumento nos teores de matéria orgânica e proteína bruta dos fenos de capim-buffel, atingindo os maiores valores com a utilização de 4,0\% de ureia, com $90,96 \%$ e $14,03 \%$ para matéria orgânica e proteína bruta, respectivamente. A aplicação de ureia não proporciona diminuição em relação às perdas de matéria seca, exceto na dose de 1,0\%, no entanto, é eficiente em reduzir a população de mofos e leveduras e elevar os teores de proteína bruta de fenos de capim-buffel.

Palavras-chave: aditivos, amonização, cenchrus ciliaris, conservação de forragens, mofos e leveduras

\section{SUMMARY}

The objective of this study was to quantify the population of molds and yeasts, evaluate losses dry matter and chemical composition of buffelgrass hay ammoniated with urea. We used a completely randomized design with five treatments and five replicates. The treatments consisted the urea levels $(0,0.5,1.0,2.0$, and $4.0 \%$ ) that were added to the hay bales based on dry matter. The inclusion of $1.0 \%$ of urea increased dry matter recovery $(93.21 \%)$ compared to non-ammoniated hay. There was quadratic effect for the $\mathrm{pH}$ with highest value observed at the level of $0.5 \%$ of urea (8.88), reducing the other levels of urea. The addition of urea levels was efficient to reduce the population of molds and yeasts, reducing from $6.50 \mathrm{log} \mathrm{CFU} / \mathrm{g}$ in untreated hay with urea to $3.65 \log$ CFU/g when added $4 \%$ of urea in the hay. The addition of urea resulted in increased contents of organic matter and crude protein hay buffelgrass, reaching the highest values with the use de $4.0 \%$ of urea, with $90.96 \%$ and $14.03 \%$, respectively. The application of urea does not provide decreased in respect losses of dry matter, except at a level of $1.0 \%$, however it is efficient in to reduce the population of molds and yeasts and elevate the crude protein of buffel grass hay.

Keywords: additivies, ammoniation, cenchrus ciliares, forage conservation, molds and yeasts 


\section{INTRODUÇÃO}

A disponibilidade de forragem no Semiárido durante o ano é desuniforme, levando à escassez de alimento na maior parte do ano, afetando negativamente a pecuária local, caracterizando o que chamamos de sazonalidade da produção de forragem, devido aos fatores climáticos característicos dessa região.

$\mathrm{O}$ uso de forrageiras adaptadas às regiões semiáridas é importante para tornar possível a produção de volumosos nessa região, dentre essas, o capim-buffel (Cenchrus ciliaris) é uma gramínea promissora, devido às suas características de adaptação a essa região. O capim-buffel apresenta maior resistência ao déficit hídrico dentre as gramíneas cultivadas nas regiões secas devido à sua eficiência no uso da água, em função de adaptações morfofisiológicas, permitindo um crescimento rápido no início do período chuvoso, após sofrer déficit hídrico intenso e prolongado (MEDEIROS \& DUBEUX JR., 2008).

Uma das alternativas para solucionar a falta de disponibilidade de forragem no período seco é a fenação, que consiste na conservação do valor nutritivo da forragem através da rápida desidratação, uma vez que a atividade respiratória das plantas, bem como a dos microrganismos é paralisada, deste modo, o excesso de forragem produzido no período chuvoso pode ser conservado. Aliado à fenação, alguns pesquisadores têm utilizado aditivos, visando melhorias no processo de conservação, assim como na qualidade do material armazenado.

$\mathrm{O}$ uso de ureia, além de reduzir o crescimento de microrganismos em fenos, pode elevar o valor nutritivo de volumosos de baixa qualidade, através da solubilização dos constituintes da parede celular vegetal, diminuindo as frações fibrosas e melhorando o consumo pelos animais (PADUA et al., 2011). Gobbi et al. (2005), avaliando a composição química do feno de Brachiaria decumbens tratada com ureia, observaram uma redução nos teores de fibra em detergente neutro e ácido e lignina com o aumento do nível de ureia utilizado. Outra característica importante da ureia é sua atividade fúngica, o que proporciona uma redução na deterioração dos fenos armazenados. A falta de informações pertinentes do valor nutritivo e das perdas do capimbuffel na forma de feno e, principalmente, com a utilização de aditivos, vem sendo um obstáculo para o melhor planejamento de como manejar essa gramínea.

Deste modo, objetivou-se quantificar a população de mofos e leveduras e avaliar as perdas de matéria seca e a composição bromatológica de fenos de capim-buffel amonizado com ureia.

\section{MATERIAL E MÉTODOS}

O experimento foi desenvolvido na Estação Experimental Pendência, da Empresa Estadual de Pesquisa Agropecuária da Paraíba S.A - Emepa, situada na mesorregião do Agreste paraibano, microrregião do Curimataú, município de Soledade, nas coordenadas de $7^{\circ} 8^{\prime} 18^{\prime \prime}$ e $36^{\circ} 27^{\prime} 2^{\prime \prime}$ W.Gr., com altitude de $534 \mathrm{~m}$. Baseado na classificação de Köppen, o tipo climático da região é Bsh, umidade relativa do ar em torno de $68 \%$, ocorrendo precipitação média de $400 \mathrm{~mm}$ anuais, com déficit hídrico durante quase todo ano.

Foi utilizado um pasto de capim-buffel (Cenchrus ciliaris), já implantado há 28 anos, em uma área cujo solo foi classificado como Luvissolo, com 
textura média e baixo teor de matéria orgânica.

$\mathrm{O}$ solo apresentou os seguintes atributos químicos (0 -20cm de profundidade): $\mathrm{pH}$ em água $=6,23$; Fósforo $=6,09$, Potássio $=216\left(\mathrm{mg} / \mathrm{dm}^{3}\right) ;$ Cálcio trocável $=3,85$, Magnésio trocável $=1,7$, Soma de bases $=6,18, \quad \mathrm{H}^{+}+\mathrm{Al}^{+3}=1,40, \quad \mathrm{CTC}=$ $7,58\left(\mathrm{cmol}_{\mathcal{C}} / \mathrm{dm}^{3}\right) ;$ Alumínio trocável $=$ 0,0 ; Saturação por bases $=81,53(\%)$.

Foi realizada uma adubação no dia 23 de junho de 2012, início do experimento, momento em que o pasto foi cortado na altura de $10 \mathrm{~cm}$ do solo para uniformização, com $50 \mathrm{~kg} / \mathrm{ha}$ de nitrogênio $(\mathrm{N})$ na forma de sulfato de amônio.

A temperatura do ar média, durante o período experimental, variou de $22,5^{\circ} \mathrm{C}$ durante a parte da manhã (7h) a $30,5^{\circ} \mathrm{C}$ durante a tarde (14h). A umidade relativa do ar oscilou entre $92 \%$ pela manhã e $60 \%$ à tarde, nos mesmos horários. A precipitação pluvial total durante o período experimental foi de $147 \mathrm{~mm}$, sendo demonstrada a seguir na Figura 1.

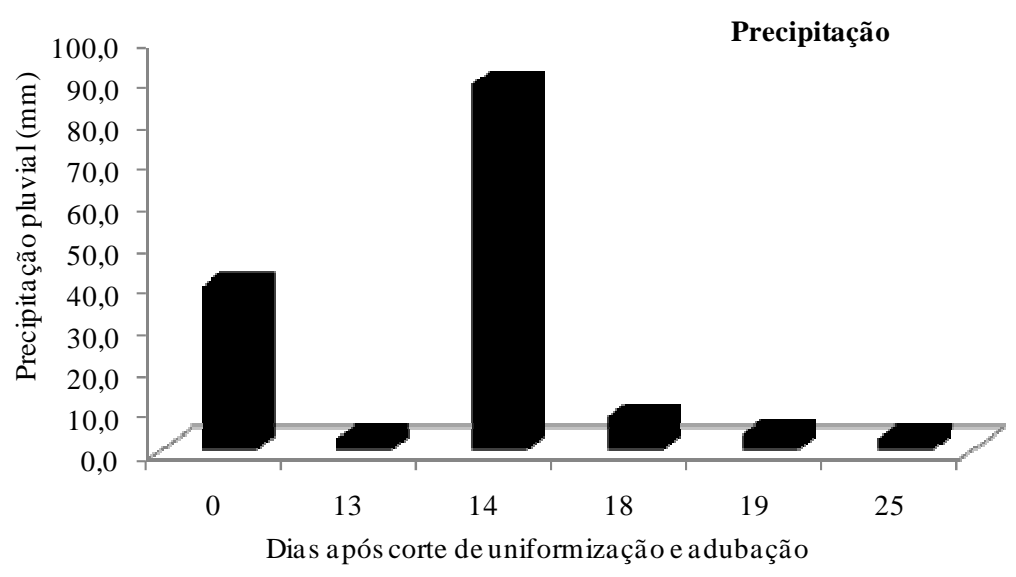

Figura 1. Precipitação pluvial em função dos dias de experimento

Foi utilizado um delineamento experimental inteiramente casualizado, com cinco tratamentos e cinco repetições. Os tratamentos compreenderam os níveis de ureia $(0 ; 0,5 ; 1,0 ; 2,0 ; 4,0 \%)$ que foram adicionados aos fardos de feno do capim-buffel. As unidades experimentais apresentavam $2 \times 2 \mathrm{~m}$, totalizando $4 \mathrm{~m}^{2}$.

Foi realizada a colheita quando o capim atingia a altura de $50 \mathrm{~cm}$, com auxílio de segadora costal, a $10 \mathrm{~cm}$ do solo, com 30 dias após o corte de uniformização.

Para avaliação da produtividade total de forragem, foi cortado todo o material de uma área de $1 \mathrm{~m}^{2}$, a $10 \mathrm{~cm}$ do solo e, em seguida, pesado para estimar a produtividade de matéria natural $(\mathrm{PMN})$, posteriormente foi realizado o cálculo para $\mathrm{kg} / \mathrm{ha}$. Uma parte da amostra de forragem foi destinada à determinação da matéria seca (MS), segundo Detmann et al. (2012). A produção em matéria seca foi estimada pelo produto entre a PMN e o teor de MS, sendo, posteriormente, convertida em produção de matéria seca por hectare.

O capim colhido foi exposto ao ambiente para a desidratação até atingir o ponto de feno, em torno de $15 \%$ de umidade. $\mathrm{O}$ material foi revolvido a cada 2 horas durante o dia com o intuito 
de uniformizar e acelerar o processo de desidratação.

Posteriormente, o material foi enfardado com auxílio de uma enfardadeira de madeira com dimensões de $25 \times 40 \times 40$ $\mathrm{cm}$, de altura, comprimento e largura, respectivamente. Após a confecção dos fardos, os mesmos foram pesados e em seguida, procedeu-se o tratamento com os respectivos níveis de ureia. A quantidade de ureia pecuária por tratamento foi diluída em $450 \mathrm{~mL}$ de água, com o objetivo de aumentar o conteúdo de umidade da forragem de $15 \%$ para $25 \%$. A aplicação foi realizada por meio de regadores, priorizando a distribuição homogênea de modo a garantir que todo o material tivesse contato com a solução. Imediatamente após a aplicação, os fardos foram cobertos por lona de polietileno e fechados com fita adesiva impedindo a entrada de ar.

Após 60 dias de armazenamento, procedeu-se a retirada da lona e os fardos foram expostos ao ar durante cerca de 4 horas para a eliminação da amônia que não reagiu com o feno. Passadas às quatro horas, os fardos foram novamente pesados para posterior cálculo das perdas.

A recuperação da matéria seca após armazenamento (RMSa) foi calculada através da seguinte equação:

$\mathrm{RMSa}(\mathrm{dag} / \mathrm{kg}) \quad=$ MFaa*MSaa / $\mathrm{MFa}^{*} \mathrm{MSa} * 100$, onde:

MFaa $=$ massa de forragem após o armazenamento (kg);

MSaa = teor de matéria seca após o armazenamento (dag/kg);

$\mathrm{MFa}=$ massa de forragem antes do armazenamento $(\mathrm{kg})$;

$\mathrm{MSa}=$ teor de matéria seca antes do armazenamento (dag/kg);

A determinação do $\mathrm{pH}$ foi realizada segundo metodologia descrita por Bolsen (1992). Em 100mL de água destilada foram adicionados $25 \mathrm{~g}$ de feno, permanecendo em repouso por $1 \mathrm{~h}$, para leitura de $\mathrm{pH}$, utilizando-se um potenciômetro.

A enumeração de mofos e leveduras foi realizada a partir de $10 \mathrm{~g}$ de uma amostra de feno adicionadas $90 \mathrm{~mL}$ de água destilada, e homogeneizadas em liquidificador industrial durante 1 minuto, obtendo-se a diluição de $10^{-1}$. Em seguida, diluições sucessivas foram realizadas, objetivando-se obter diluições variando de $10^{-1}$ a $10^{-7}$. Foi utilizado o meio de cultura Batata Dextrose Agar, acrescido de 1\% de ácido tartárico a $10 \%$. O plaqueamento foi realizado em duplicata em placas de petri estéreis. A contagem de mofos e leveduras foi realizada após incubação por período de 3-7 dias à temperatura ambiente. Foram consideradas passíveis de contagem as placas com valores entre 30 e 300 unidades formadoras de colônia (UFC).

Para determinação da composição química, coletou-se aproximadamente $300 \mathrm{~g}$ de feno após o período de armazenamento, visando-se obter a composição do feno após todas as etapas do processo de fenação, o qual seria utilizado na alimentação animal. As amostras foram pré-secas em estufa de ventilação forçada a $60^{\circ} \mathrm{C}$, até atingir peso constante. Posteriormente, as amostras foram moídas em moinho de facas com peneira de $1 \mathrm{~mm} e$ acondicionadas em frascos de plástico.

A partir destas amostras, foram realizadas as determinações de MS, matéria orgânica (MO) e fibra em detergente neutro (FDN) segundo Van Soet et al. (1967); proteína bruta (PB) (AOAC, 1975) e extrato etéreo (EE), segundo metodologias descritas por Silva e Queiroz, 2002). A determinação de carboidratos solúveis (CHOs) foi realizada segundo Corsato et al. (2008). Foram calculados os teores de carboidratos totais $(\mathrm{CT}=100-(\% \mathrm{~PB}+$ 
$\% \mathrm{EE}+\% \mathrm{MM})$ e dos carboidratos não fibrosos $(\mathrm{CNF}=\mathrm{CT}-\mathrm{FDNcp})$. As análises laboratoriais foram realizadas no laboratório de Análise e Avaliação de Alimentos do Centro de Ciências Agrárias (CCA) da Universidade Federal da Paraíba (UFPB).

Os dados obtidos foram submetidos à análise de variância e regressão. O efeito dos níveis de ureia foi avaliado por meio de análise de regressão, tomando-se como critério para escolha dos modelos, os valores dos coeficientes de determinação e a significância dos parâmetros da regressão, testados pelo teste Tukey, ao nível de $5 \%$ de significância, utilizando-se o Sistema de Análises Estatísticas e Genéticas (UFV, 2007).

\section{RESULTADOS E DISCUSSÃO}

A produção de matéria seca (Tabela 1) alcançou $5.686,38 \mathrm{~kg} / \mathrm{ha}$ colhido a $50 \mathrm{~cm}$ de altura. Vale ressaltar que essa produção foi alcançada com uma precipitação total de $147 \mathrm{~mm}$.

Tabela 1. Valores médios da produção de matéria verde (PMV) e matéria seca (PMS), do capim-buffel colhido para fenação

\begin{tabular}{lc}
\hline Variáveis & $(\mathrm{kg} / \mathrm{ha})$ \\
\hline PMV & $31.264,00$ \\
PMS & $5.686,38$ \\
\hline
\end{tabular}

$\mathrm{CV}=$ coeficiente de variação.

Não houve ajuste de modelos lineares para os valores de recuperação de matéria seca após a abertura (Tabela 2), com a adição de níveis de ureia no feno de capim-buffel. Observa-se que a inclusão de ureia na dose de 1,0\% elevou a RMS $(93,21 \%)$ em relação ao feno não amonizado. No entanto, nos demais níveis de inclusão de ureia foram observados maiores perdas de matéria seca quando comparado ao tratamento controle $(0 \%$ de ureia), demonstrando que a amonização não reduziu as perdas de matéria seca durante o armazenamento. Essas perdas de matéria seca podem ter ocorrido pela continuação da respiração celular e não ao desenvolvimento de fungos, uma vez que esse grupo microbiano diminuiu com a amonização.

Observou-se efeito significativo $(\mathrm{P}<0,05)$ para o $\mathrm{pH}$ (Tabela 2), entretanto não houve ajuste de modelo, o maior valor observado $(8,88)$, para o nível de $0,5 \%$ de ureia, porém, todos com valores são considerados altos para esta variável. Segundo Carvalho et al. (2006), a elevação do pH em materiais amonizados pode ser atribuída ao fato de a amônia ser uma base com alta capacidade tamponante, evitando, portanto, que a produção de ácido provoque queda acentuada do $\mathrm{pH}$. A amônia liberada nesse processo inibe a proliferação de microrganismos indesejáveis, como fungos e leveduras, o que foi observado no presente estudo. A adição de níveis de ureia foi eficiente na redução da população de mofos e leveduras, reduzindo de 6,50 log UFC/g no feno sem tratamento com ureia para $3,65 \log$ UFC/g quando adicionados $4 \%$ de ureia no feno, demonstrando o efeito fungistático da amonização (Tabela 2). Observou-se maior redução no número de UFC de M e L no feno de capimbuffel, nos níveis de inclusão de 2 e $4 \%$ de ureia. Almeida et al. (2006), observaram que a adição de $2 \%$ de ureia foi suficiente para inibir o crescimento de fungos, em fenos de grama-batatais (Paspalum notatum). 
Tabela 2. Valores médios da enumeração de mofos e leveduras ( $\mathrm{M}$ e $\mathrm{L}$ ), pH e RMS (Recuperação de matéria seca) em fenos de capim-buffel amonizados com ureia

\begin{tabular}{cccc}
\hline $\begin{array}{c}\text { Níveis de } \\
\text { ureia } \\
\text { (\% na MS) }\end{array}$ & $\begin{array}{c}\text { RMS } \\
(\%)\end{array}$ & pH & $\begin{array}{c}\text { M e L } \\
(\log \\
\text { UFC/g) }\end{array}$ \\
\hline 0 & 92,86 & 8,25 & 6,50 \\
0,5 & 86,24 & 8,88 & 5,45 \\
1,0 & 93,21 & 8,03 & 5,85 \\
2,0 & 87,27 & 8,05 & 3,78 \\
4,0 & 88,43 & 7,97 & 3,65 \\
\hline
\end{tabular}

É importante considerar que a região onde foi desenvolvida esta pesquisa, apesar de ser semiárido, apresenta elevadas taxas para umidade relativa do ar (92\%), favorecendo o desenvolvimento de fungos que podem colaborar ainda mais para as alterações na composição química e as perdas de matéria seca. Além disso, esses fungos podem ser prejudiciais à saúde dos animais e das pessoas que manuseiam estes fenos, devido à produção de toxinas.

Para os teores de MS (Figura 4) houve um efeito linear $(\mathrm{P}<0,05)$, decrescendo à medida que aumentaram as doses de ureia. Este decréscimo da MS está relacionado à adição de água que foi utilizada como veículo para incorporação da ureia aos fardos.

A MO apresentou um efeito linear $(\mathrm{P}<0,05)$, aumentando com a utilização das doses de ureia, acontecimento este que ocorreu devido ao acréscimo nos teores de proteína à medida que foi adicionada ureia.

Os valores de PB aumentaram linearmente $(\mathrm{P}<0,05)$, este fato está associado à retenção do nitrogênio no feno através da atividade ureolítica, que transforma a ureia em amônia e dessa forma a retém no material segundo Schmidt et al. (2003). Zanine et al. (2007), utilizando a ureia como fonte para amonização de capim-tanzânia, com níveis de 1,2 e $3 \%$ na MS, observaram aumentos nos teores de PB em torno de $4 \%$ com a maior de dose de ureia aplicada comparado ao tratamento controle.

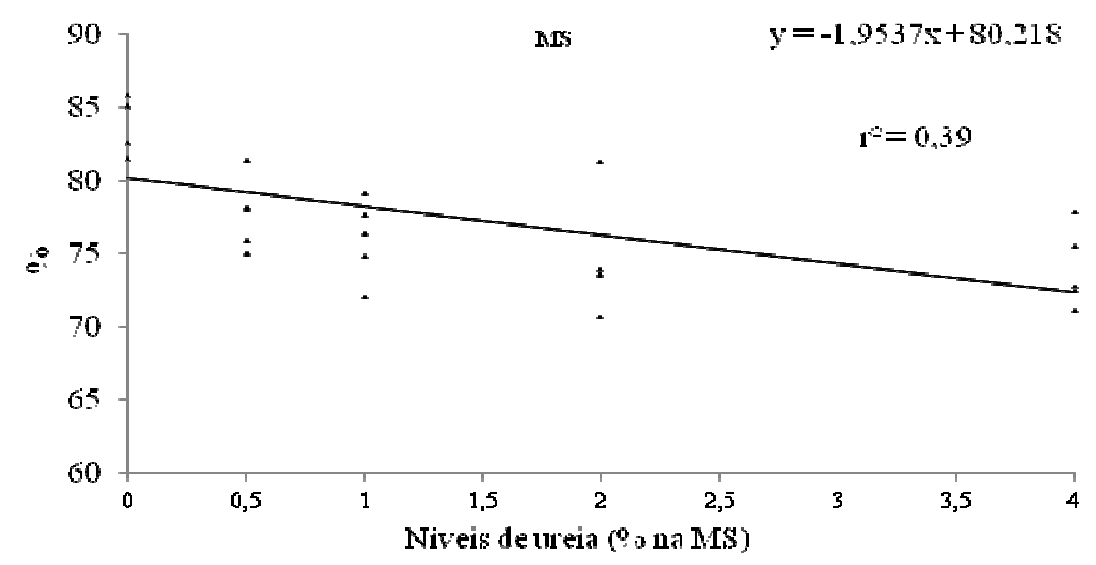

Figura 4. Percentuais médios de matéria seca (MS) em fenos de capim-buffel amonizados com ureia 
Rev. Bras. Saúde Prod. Anim., Salvador, v.15, n.3, p.561-569 jul./set., 2014 http://www.rbspa.ufba.br ISSN 15199940

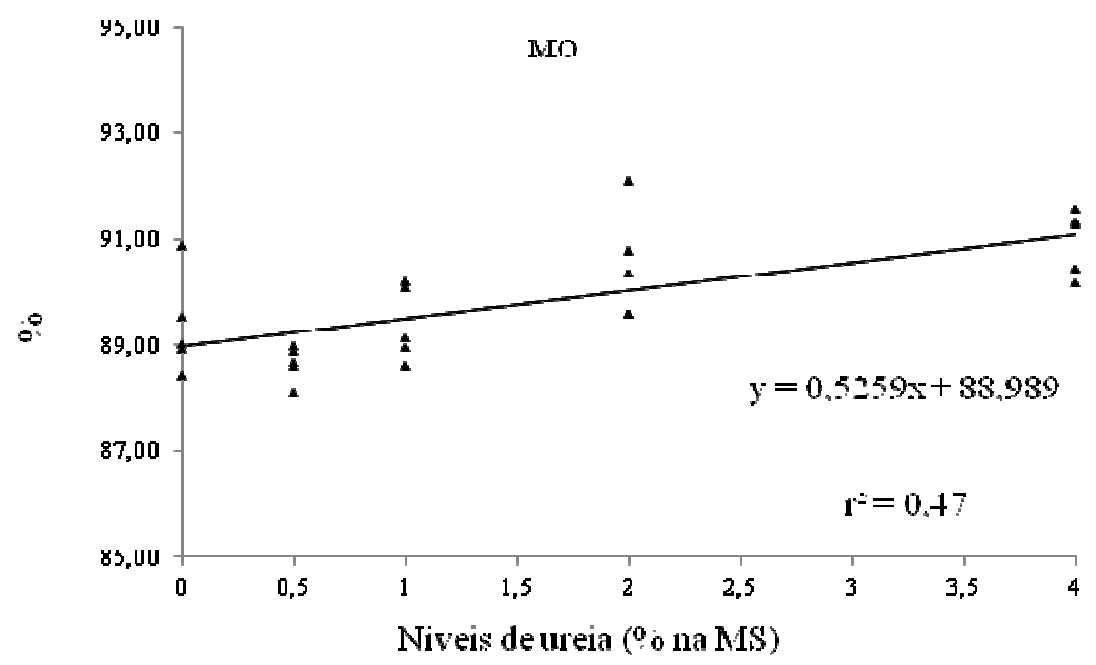

Figura 5. Percentuais médios de matéria orgânica (MO) em fenos de capim-buffel amonizados com ureia

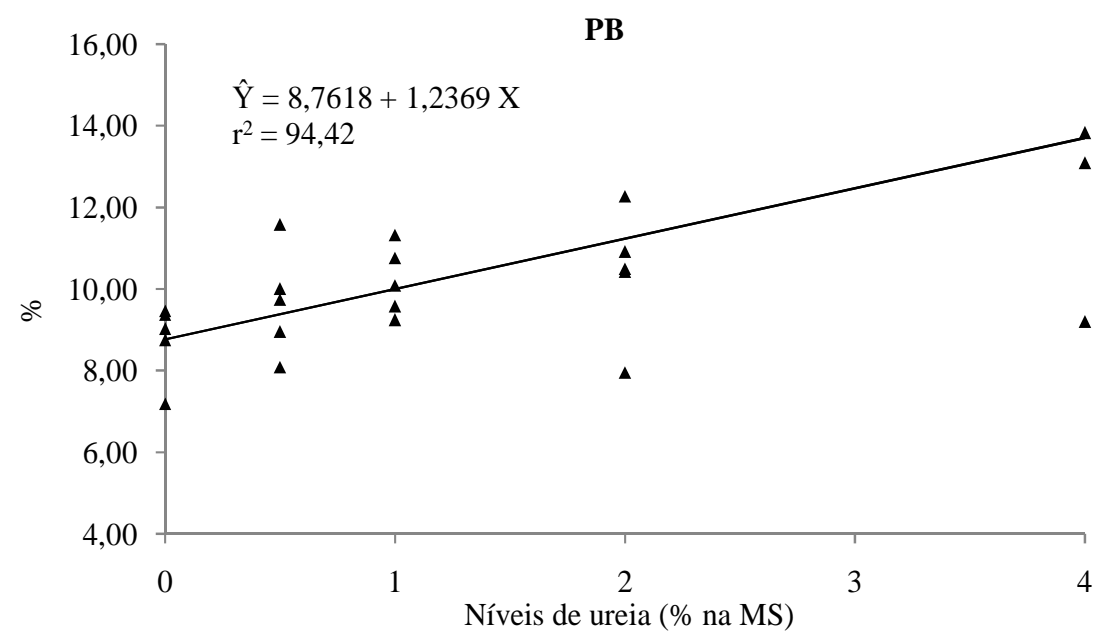

Figura 6. Percentuais médios de proteína bruta (PB) em fenos de capim-buffel amonizados com ureia

Entretanto, observou-se que, à medida que se elevou a quantidade de ureia aplicada, menor foi o aumento de PB, possivelmente devido a maiores perdas por volatilização do $\mathrm{N}$, na forma de amônia, com os níveis mais altos, tal fato também foi observado por Gobbi et al. (2005) e por Reis Junior et al. (2011) que encontraram maior valor de retenção de $\mathrm{N}$ para os níveis mais baixos de ureia, demonstrando que a fixação do $\mathrm{N}$ aplicado varia, em função da quantidade de ureia adicionada, sendo registrados maiores valores de retenção com o uso de níveis menores. Para os valores de CHOT, FDN, CNF e $\mathrm{EE}$ não foram observados efeito significativo $(\mathrm{P}>0,05)$ com o aumento dos níveis de ureia (Tabela 3). Com relação aos valores de FDN, era esperada uma redução devido à hidrólise de seus componentes que é intensificado quando se incorpora amônia no material. Schmidt et al. 
Rev. Bras. Saúde Prod. Anim., Salvador, v.15, n.3, p.561-569 jul./set., 2014 http://www.rbspa.ufba.br ISSN 15199940

(2003), trabalhando com feno de brachiaria decumbens tratado quimicamente com ureia, observaram que não houve uma diminuição nos teores médios de FDN, corroborando com o resultado encontrado neste trabalho.

Tabela 3. Percentuais médios de carboidratos totais (CHOT), fibra em detergente neutro (FDN), carboidratos não fibrosos (CNF) e extrato etéreo (EE) em fenos de capim-buffel amonizados com ureia

\begin{tabular}{lcccccc}
\hline \multirow{2}{*}{ Variáveis } & \multicolumn{7}{c}{ Doses de ureia (\% MS) } & \multirow{2}{*}{ CV $(\%)$} \\
\cline { 2 - 6 } & 0 & 0,5 & 1 & 2 & 4 & \\
\hline CHOT (dag/kg) & 78,77 & 77,11 & 77,39 & 78,50 & 75,28 & 6,58 \\
FDN (dag/kg) & 65,67 & 66,50 & 64,30 & 64,93 & 64,43 & 7,39 \\
CNF (dag/kg) & 13,10 & 10,61 & 13,10 & 13,80 & 13,58 & 7,69 \\
EE (dag/kg) & 1,83 & 1,88 & 1,82 & 1,58 & 1,65 & 9,03 \\
\hline
\end{tabular}

A ineficiência da ureia em diminuir os teores da fração fibrosa nos fenos de capim-buffel pode estar relacionada com o estádio de desenvolvimento avançado do mesmo no momento da colheita, que pode ter reduzido a atividade da urease, diminuindo a liberação de amônia e, consequentemente, a solubilização da hemicelulose. $\mathrm{O}$ mesmo pode explicar a ausência de efeito no CNF, sabendo que a amonização do feno pode promover uma solubilização parcial dos constituintes da parede celular, resultando em incremento no conteúdo na fração de carboidratos potencialmente digestíveis (VAN SOEST, 1994).

A aplicação de ureia não proporciona benefícios em relação à recuperação de matéria seca, exceto na dose de $1,0 \%$, no entanto, é eficiente em reduzir a população de mofos e leveduras e aumenta o teor de PB em fenos de capimbuffel.

\section{REFERÊNCIAS}

ALMEIDA, J.C.C.; PÁDUA, F.T.; NEPOMUCENO, D.D.; ROCHA, N.S.; SILVA, T.O.da; ZANINE, A.de M. Ocorrência de fungos no feno de gramabatatais (Paspalum notatum) em função da dose de ureia, período de tratamento e do teor de umidade. Livestock Research for Rural Development, v.18, n.80, 2006.

ASSOCIATION OF OFFICIAL ANALYTICAL CHEMISTS - AOAC. Official Methods of Analysis.

Washington, 1975.1094p.

BOLSEN, K.K.; LIN, C.; BRENT, C.R.; FEYERHERM, A.M.; URBAN, J.E.; AIMUTIS, W.R. Effects silage additives on the microbial succession and fermentation process of alfalfa and corn silages. Journal of Dairy Science, v.75, n.11, p.3066-83, 1992. 
Rev. Bras. Saúde Prod. Anim., Salvador, v.15, n.3, p.561-569 jul./set., 2014 http://www.rbspa.ufba.br ISSN 15199940

CARVALHO, G.G.P.; PIRES, A.J.; VELOSO, C.M.; MAGALHÃES, A.F.; FREIRE, M.A.L.; SILVA, F.F. da; SILVA, R.R.; CARVALHO, B.M.A.de. Valor nutritivo do bagaço de cana-deaçúcar amonizado com quatro doses de uréia. Pesquisa Agropecuária

Brasileira, v.41, n.1, p.125-132, 2006.

CORSATO, C.E.; SCARPARE FILHO, J.A.; SALES, E.C.J. Teores de carboidratos em órgãos lenhosos do caquizeiro em clima tropical. Revista Brasileira de Fruticultura, v.30, n.2, p.414-418, 2008.

GOBBI, K.F.; GARCIA, R.; GARCEZ NETO, A.F.; PEREIRA, O.G.; BERNARDINO, F.S.; ROCHA, F.C. Composição química e digestibilidade In Vitro do feno de Brachiaria decumbens Stapf. tratado com ureia. Revista Brasileira de Zootecnia, v.34, n.3, p.720-725, 2005.

MEDEIROS, H.R.; DUBEUX JUNIOR, J.C.B. Efeitos da fertilização com nitrogênio sobre a produção e eficiência do uso da água em capim buffel. Revista Caatinga, v.21, n.3, p.13-15, 2008.

PADUA, F.T.; ALMEIDA, J.C.C.; NEPOMUCENO, D.D.; CABRAL NETO, O.; DEMINICIS, B.B. Efeito da dose de uréia e período de tratamento sobre a composição do feno de paspalum notatum. Archivos de Zootecnia, v.60, n.29, p. 57-62, 2011.

REIS Jr, L.C.V.; ALMEIDA, J.C.C.; ARAÚJO, R.P.; LISTA, F.N.; RIBEIRO, E.T.; MENDONÇA, D.C.de; ABREU, J.B.R.de; ARAÚJO, S.A.do
C.; RIBEIRO, T.P. Qualidade do Feno de Capim Coast-Cross sob Níveis de ureia e Períodos de Amonização.

Revista de Ciências da Vida, v.31, n.1, p.71-80, 2011.

SCHMIDT, P.; WECHSLER, F.S.; VARGAS JUNIOR, F.M.V.; ROSSI, P. Valor Nutritivo do Feno de Braquiária Amonizado com Uréia ou Inoculado com Pleurotus ostreatus. Revista Brasileira de Zootecnia, v.32, n.6, p.2040-2049, 2003.

SILVA, D.J.; QUEIROZ, A.C. de. Análises de alimentos: métodos químicos e biológicos. 3. ed. Viçosa: Universidade Federal de Viçosa, 2002. 235p.

UNIVERSIDADE FEDERAL DE VIÇOSA-UFV. SAEG. Sistema para Análises Estatísticas. Versão 9.1. Viçosa, 2007.

VAN SOEST, P.J. Development of a comprehensive system of feed analysis and its application to forage. Journal of Animal Science, v.26, n.1, p.119-120, 1967.

VAN SOEST, P.J. Nutritional ecology of the ruminant. 2nd ed. Ithaca: Cornell University Press, 1994. 476p.

ZANINE, A.M.; SANTOS, E.M.; FERREIRA, D.J.; PEREIRA, O.G. Efeito dos níveis deuréia sobre o valor nutricional do feno de capim-Tanzânia. Semina: Ciências Agrárias, v.28, n.2, p.333-340, 2007.

Data de recebimento: 02/12/2013

Data de aprovação: 08/09/2014 